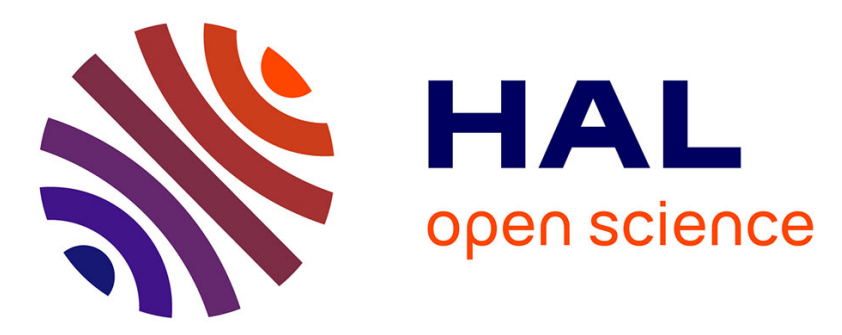

\title{
Nanoscale Mapping of the Physical Surface Properties of Human Buccal Cells and Changes Induced by Saliva
}

\author{
Ece Neslihan Aybeke, Sarah Ployon, Marine Brulé, Brice de Fonseca, Eric
}

Bourillot, Martine Morzel, Eric Lesniewska, Francis Canon

\section{To cite this version:}

Ece Neslihan Aybeke, Sarah Ployon, Marine Brulé, Brice de Fonseca, Eric Bourillot, et al.. Nanoscale Mapping of the Physical Surface Properties of Human Buccal Cells and Changes Induced by Saliva. Langmuir, 2019, 35 (39), pp.12647-12655. 10.1021/acs.langmuir.9b01979 . hal-02405320

\author{
HAL Id: hal-02405320 \\ https://hal.science/hal-02405320
}

Submitted on 26 May 2020

HAL is a multi-disciplinary open access archive for the deposit and dissemination of scientific research documents, whether they are published or not. The documents may come from teaching and research institutions in France or abroad, or from public or private research centers.
L'archive ouverte pluridisciplinaire $\mathbf{H A L}$, est destinée au dépôt et à la diffusion de documents scientifiques de niveau recherche, publiés ou non, émanant des établissements d'enseignement et de recherche français ou étrangers, des laboratoires publics ou privés. 
Subscriber access provided by INRA Institut National de la Recherche Agronomique

\section{Interfaces: Adsorption, Reactions, Films, Forces, Measurement Techniques, Charge}

Transfer, Electrochemistry, Electrocatalysis, Energy Production and Storage

Nanoscale mapping of the physical surface properties of human buccal cells and changes induced by saliva

Ece Neslihan Aybeke, Sarah Ployon, Marine Brulé, Brice de Fonseca, Eric Bourillot, Martine Morzel, Eric Lesniewska, and Francis Canon

Langmuir, Just Accepted Manuscript • DOI: 10.1021/acs.langmuir.9b01979 • Publication Date (Web): 25 Aug 2019

Downloaded from pubs.acs.org on September 18, 2019

\section{Just Accepted}

"Just Accepted" manuscripts have been peer-reviewed and accepted for publication. They are posted online prior to technical editing, formatting for publication and author proofing. The American Chemical Society provides "Just Accepted" as a service to the research community to expedite the dissemination of scientific material as soon as possible after acceptance. "Just Accepted" manuscripts appear in full in PDF format accompanied by an HTML abstract. "Just Accepted" manuscripts have been fully peer reviewed, but should not be considered the official version of record. They are citable by the Digital Object Identifier (DOIB). "Just Accepted" is an optional service offered to authors. Therefore, the "Just Accepted" Web site may not include all articles that will be published in the journal. After a manuscript is technically edited and formatted, it will be removed from the "Just Accepted" Web site and published as an ASAP article. Note that technical editing may introduce minor changes to the manuscript text and/or graphics which could affect content, and all legal disclaimers and ethical guidelines that apply to the journal pertain. ACS cannot be held responsible for errors or consequences arising from the use of information contained in these "Just Accepted" manuscripts. 


\title{
Nanoscale mapping of the physical surface
}

\section{properties of human buccal cells and changes}

\author{
induced by saliva
}

\author{
Ece Neslihan Aybeke ${ }^{1}$, Sarah Ployon ${ }^{1}$, Marine Brulél, Brice De \\ Fonseca², Eric Bourillot², Martine Morzel1, Eric Lesniewska², \\ Francis Canon ${ }^{1}$
}

AUTHOR ADDRESS

${ }^{1}$ Centre des Sciences du Goût et de l'Alimentation, CNRS, INRA, Université de Bourgogne Franche-Comté, Dijon, France 2 ICB UMR CNRS 6303, Université de Bourgogne Franche-Comté, Dijon, France

KEYWORDS. Atomic force microscopy, scanning microwave microscopy, oral epithelial cells, mucosal pellicle, mucins, cell hydrophobicity, salivary proteins. 
ABSTRACT

The mucosal pellicle, also called salivary pellicle, is a thin biological layer made of salivary and epithelial constituents, lining oral mucosae. It contributes to their protection against microbiological, chemical or mechanical insults. Pellicle formation depends on the cells' surface properties, and in turn the pellicle deeply modifies such properties. It has been reported that the expression of the transmembrane mucin MUC1 in oral epithelial cells improves the formation of the mucosal pellicle. Here, we describe an approach combining classical and functionalized tip atomic force microscopy and scanning microwave microscopy to characterize how MUC1 induces changes in buccal cells' morphology, hydrophobicity and electric properties to elucidate the physicochemical mechanisms involved in the enhancement of the anchoring of salivary proteins. We show that MUC1 expression did not modify drastically the morphology of the epithelial cells' surface. MUCl expression, however, resulted in the presence of more hydrophobic and more charged areas at the cell surface. The presence of salivary proteins decreased the highest attractive and repulsive forces recorded between the cell surface and a functionalized hydrophobic AFM tip, suggesting that the most hydrophobic and charged areas participate in the binding of salivary proteins. The cells' dielectric properties were 


\begin{abstract}
altered by both MUC1 expression and the presence of a mucosal pellicle. We finally show that in absence of MUC1, the pellicle appeared as a distinct layer poorly interacting with the cells' surface. This integrative AFM/SMM approach may usefully describe the surface properties of various cell types, with relevance to the bioadhesion or biomimetics fields.
\end{abstract}


TEXT

\section{Introduction}

Mucosal surfaces, which line various body cavities (eye, mouth, nose, vagina...) or internal organs (lungs, stomach, gut...), represent the first line of defense against invading pathogens and xenobiotics. They also ensure protection against mechanical wear and dehydration though their lubricating properties. These functions are partly fulfilled by a mucous layer covering the often mucin-secreting epithelial cells. The situation differs slightly for the mucosal surfaces of the oral cavity, where epithelial cells are lined by a thin biological layer, up to $100 \mathrm{~nm}$ high, made of both epithelial and salivary constituents. This biological structure termed the mucosal or salivary pellicle is constituted through selective adsorption of salivary proteins (MUC5B, MUC7, sIgA etc.) onto the cell's surface ${ }^{[1]}$. Among those, the heavily glycosylated mucins MUC5B are prominently involved in the lubricating and hydrating properties of the pellicle ${ }^{[2]}$. Adsorption of MUC5B and other salivary proteins to the cells' surface is suggested to occur mainly through non-covalent (in particular hydrophobic) interactions ${ }^{[3]}$. We have also showed that the presence of the transmembrane mucin MUC1 enhances anchoring of MUC5B onto the cell's surface [4], suggesting that protein-protein interactions between MUC1 and salivary proteins are also involved 
in the mucosal pellicle formation. Cross-linking between salivary proteins mediated by transglutaminase further consolidates the architecture of the pellicle ${ }^{[1 a]}$.

Oral mucosal surfaces play a role in the perception of food sensory attributes, in particular astringency or aroma persistence. For both sensations, the suggested mechanism by which the oral surface intervenes relies on the ability of the cell surface and mucosal pelicle constituents to interact noncovalently with tannins ${ }^{[5]}$ or aroma compounds ${ }^{[6]}$. Noncovalent interactions can be of different natures (hydrophobic effect, electrostatic interactions, Van der Waals forces or $\Pi$-effects), depending on the structure and physico-chemical properties of the partners.

Therefore, determining the physicochemical characteristics of epithelial cells and mucosal surfaces may help understanding further the nature of non-covalent interactions involved both in the anchoring of salivary proteins forming the mucosal pellicle and in flavor perception. More generally, such information would be of great importance to gain deeper knowledge on the phenomenon of bioadhesion on oral soft surfaces.

To study in vitro biological events involving the mucosal surface, we have recently developed a cellular model of oral mucosa surmounted by a mucosal pellicle. The model is based on the use of 
TR146 cells which have been stably transfected to express the transmembrane mucin MUC1, incubated with human saliva. We have demonstrated that MUC1 expression increases by $30 \%$ the anchoring of salivary MUC5B at its surface[4]. This model proved useful to study the structural alterations of the mucosal pelicle induced by tannins ${ }^{[5 b]}$.

Atomic Force Microscopy (AFM) is a very high-resolution type of scanning probe microscopy which allows investigating with subnanometer resolution capacity the morphology and physicochemical properties of biological samples in their physiological environment. The AFM technique consists of scanning the surface of a sample by a sharp tip and recording the interatomic forces between the sample and the tip. AFM can be applied to a variety of biological samples such as protein assemblies ${ }^{[7]}$, viruses $^{[8]}$ or live eukaryotic cells[9] . Functionalization of AFM tips with a ligand enables probing specific interactions such as antibody-antigen or DNA-protein interactions ${ }^{[10]}$. Another AFM technique, termed scanning microwave microscopy (SMM), combines the electromagnetic measurement capabilities of a microwave vector network analyzer with the resolution power of AFM. Our laboratory has developed a network analyzer giving access to several frequencies in the range $0.1-16 \mathrm{GHz}{ }^{[11]}$. The signal characterizes the local conductance and dielectric properties of the sample, 
enabling to perform three-dimensional tomographic investigations on the electric properties of a sample. While the dielectric properties of a medium determines the strength of interactions between charged species, the dielectric properties of a surface provide indications on its ability to establish electrostatic forces. Moreover, as the dielectric micro-environments are complex and variable, SMM will provide an overview on its spatial variation both horizontally and vertically.

Here, we report an integrative approach combining classical AFM, force spectroscopy and SMM to identify the physicochemical mechanisms involved in the formation of the mucosal pellicle and characterize the influence of biological supramolecular structures (the transmembrane mucins and /or the mucosal pellicle) present at the cell surface on its physico-chemical properties. While classical AFM discriminated the structures present at the cell surface, functionalization of the probe's tip allowed evaluating the hydrophobicity of cell's surface. In parallel, the electric properties of the cell's surface were explored at resonance frequencies of $2,4.3$ and $8.6 \mathrm{GHz}$ by the SMM device. The thorough description of physico-chemical properties of the cell surface and how they are affected by the presence of mucin and salivary proteins will provide new insights into the mechanisms at the origin of bioadhesion on soft surfaces of the oral cavity. 


\begin{abstract}
Bioadhesion is crucial to maintain a healthy and comfortable hydrated mouth feeling. Any new knowledge in this field may lead to innovations in, for example, the development of oral hygiene products or saliva substitutes for patients suffering from dry mouth.
\end{abstract}

\title{
Experimental Section
}

\section{Saliva collection}

The study was performed in agreement with the guidelines of the declaration of Helsinki. Informed consent was obtained from the subjects who donated saliva. Unstimulated saliva was collected from seventeen volunteers who declared to be in good oral health. The volunteers were instructed to refrain from smoking, eating and drinking for at least two hours before the collection sessions. The collection sessions lasted 30 minutes during which volunteers spat out the saliva accumulating naturally in their mouth into plastic vessels kept on ice. All samples were pooled and centrifuged at $14000 \mathrm{~g}$ for $20 \mathrm{~min}$ at $4{ }^{\circ} \mathrm{C}$. The clarified saliva was aliquoted and frozen at $-80{ }^{\circ} \mathrm{C}$.

\section{Cell culture}


The native (TR146) and transfected (TR146/MUC1) epithelial cells were routinely grown according to the protocol described previously ${ }^{[4]}$. The cells were seeded at 4 x $10^{4}$ cells/ml density on Cell-Tak ${ }^{\mathrm{TM}}$ coated glass cover slips (Agar Scientific). The cells were incubated at $37^{\circ} \mathrm{C}$ in a humidified atmosphere containing 7.5 o $\mathrm{CO}_{2}$ for two days in order to reach confluence. The confluent cultures were incubated with clarified saliva for two hours and then washed twice with phosphate-buffered saline (PBS, pH 7.0 7.3, Gibco ${ }^{\circledR}$ ) to eliminate unbound saliva. Fixation of cells was carried out with 2.5\% glutaraldehyde (Sigma-Aldrich) in PBS (pH $7.8 \pm 0.2$, Bio-RAD) during 30 min, followed by rinsing with PBS. AFM imaging (topography and tip-sample force measurements) was performed in liquid PBS medium. SMM analysis was performed on samples processed as above and further dehydrated through graded baths of ethanol (from 30 to 100\%). Drying was performed by the critical point drying method using a Leica CPD 030 .

\section{AFM imaging}

AFM characterizations were performed using Multimode 8 AFM microscope (Bruker, Santa Barbara, CA, USA). The topographic features of cells without and with a mucosal pellicle were investigated using silicon nitride probes (ScanAsyst Air HR, $\mathrm{k}=$ $0.4 \mathrm{~N} / \mathrm{m}$ and $\mathrm{f}=70 \mathrm{kHz}$, Bruker). The topographic images were acquired at high resolution (512 x 512 pixel $^{2}$ ) using Peak force 
mode. In Peak force mode, the AFM tip oscillates at a frequency of $2 \mathrm{kHz}$ with amplitude of 20 nanometers. This mode is well adapted for imaging soft and delicate samples such as cells at high resolution.

\section{Tip - sample force measurements}

Gold-coated AFM probes were functionalized with hydrophobic selfassembled monolayers (SAMs) using alkanethiols. Forming a SAMs assembly on gold surfaces is a well-controlled process having many practical advantages ${ }^{[12]}$. The SH-groups of alkanethiols has a high affinity on gold substrates[13] via chemical binding and it can remain stable during days to weeks after its formation ${ }^{[12]}$. Goldcoated cantilevers, with the nominal spring constant of $0.12 \mathrm{~N} / \mathrm{m}$ and the nominal resonance frequency of $23 \mathrm{kHz}$, were purchased from Bruker (NPG-10, Santa Barbara, CA, USA). The self-assembled monolayers were formed on the gold-coated cantilevers according to a previous procedure[14]. Gold-coated cantilevers were immersed in $1 \mathrm{mM}$ solutions of alkanethiols terminated with $\mathrm{CH}_{3}$ (1octadecanethiol, Sigma-Aldrich) during 18 hours. Firstly, a teflon substrate (Sigma Aldrich) was scanned to verify the AFM tip functionalization. Secondly, the adhesion forces between the functionalized tips and cells were measured using contact imaging mode. AFM enables to probe the forces between the tip and sample by monitoring the deflection of the cantilever when it approaches, 
contacts and retracts from a surface. Contact imaging mode records a force curve for each contact point of tip in function of the approach - retract curves providing information about the elasticity and adhesion. The tip - sample adhesion forces were measured on 5 x $5 \mu^{2}$ of area on the cell surface by taking in account 256 × 256 contact points. Images were acquired from 4 different glass slides per condition (N, NS, T, TS).

\section{Statistical analysis for tip - sample force measurements}

To determine the characteristic adhesion forces between each sample and the hydrophobic tip, a total of 94208 force curves were recorded per sample. For each image, cumulated attractive and repulsive forces were plotted against the force intensity. The D25, D50 and D75, which correspond to the force intensity at 25, 50 and 75 percent of the cumulated force, were extracted. The average attractive and repulsive forces were also extracted. The impact of the sample type on such data was tested using one-way analysis of variance (ANOVA). When a significant difference was observed ( $\mathrm{P}$ value $<0.05$ ), means were compared using a Tukey pairwise comparison test (significance level set at 5\%).

\section{SMM imaging}

Scanning microwave microscopy combines the use of atomic force microscopy with a vector network analyzer (VNA). This 
configuration offers simultaneous measurement of the topography and complex reflection coefficient of a sample with high sensitivity. The VNA can generate microwaves in the high frequency range. The incident microwave signal is transmitted through a resonant circuit to a conductive probe. The conductive probe enables to transmit and receive microwaves from the contact point on sample. The applied microwave penetrates into the sample and a part of the signal is reflected back through the cantilever. The VNA detects the reflected signal (alternatively transmitted signal) in the reflection mode and thereby measures the complex reflection coefficient $\left(S_{11}\right)$ of the contact point. The measured $S_{11}$ value represents the local impedance resulting from the tip-sample interactions. The amplitude and phase of $\mathrm{S}_{11}$ signal are recorded for each contact point simultaneously with topographic data of the sample.

We have performed SMM analysis using a commercial AFM (Keysight 5600LS, Agilent Technologies) equipped with a vector network analyzer (VNA N5230A, Agilent Technologies). The VNA can generate microwaves ranging from $800 \mathrm{MHz}$ to $13 \mathrm{GHz}$ and detects the reflected signal from sample. Topography, VNA phase and VNA amplitude images of the samples were recorded using contact mode in ambient conditions. The surfaces of samples were scanned via a platinumiridium coated tip with nominal radius of $20 \mathrm{~nm}$ (SCM-PIT, $\mathrm{k}=2.8$ 
$\mathrm{N} / \mathrm{m}$ and $\mathrm{f}_{0}=75 \mathrm{kHz}$, Bruker) at $50 \mu \mathrm{m}$ scan size with $1 \mathrm{~Hz}$ scan rate. Each sample was analyzed at three frequencies (2 GHz, 4.3 $\mathrm{GHz}$ and $8.6 \mathrm{GHz}$. Images were acquired from 4 different glass slides per condition ( (N, NS, T, TS).

\section{Statistical analysis of SMM images}

A total of 174 SMM images were used for statistical analysis: the number of images at each frequency (2, 4.3 and $8.6 \mathrm{GHz})$ was respectively 12, 12 and 10 for native cells (N), 9, 10 and 9 for native cells with a salivary (mucosal) pellicle (NS), 17, 20 and 16 for transfected TR146/MUC1 cells (T) and 19, 19 and 21 for transfected cells with a salivary pellicle (TS). The mean values of each amplitude and phase image were obtained using AFM software [15]. One-way ANOVA was performed to evaluate at each frequency the impact of MUC1 and the mucosal pellicle on mean amplitude and phase SMM values.

\section{Impedance images}

The complex reflection coefficient was converted into complex impedance data using a Matlab script. The reflection coefficient $S_{11}$ was measured in reflection mode. In this way, a ratio of the incident / reflected electromagnetic waves was recorded by the VNA. The microwave images (amplitude and phase signals) are induced by interaction variations between the tip and the sample at every 
contact point, traducing local changes of the constituted equivalent electrical circuit. These local changes give access to nanoscale electrical impedance values of the sample, called DUT (Device Under Test).

Impedance is a complex number with strong frequency dependence. A simple method to measure impedance at microwave frequencies is to connect the DUT (here biological sample) of unknown impedance to the end of a coaxial line (here the AFM tip). The other end of the coaxial line is linked to the VNA, the microwave source. Thus the SMM measurement allows to calculate the corresponding real and imaginary impedance components by first expressing the real and imaginary parts of the reflection coefficient as follows:

$$
\begin{aligned}
& \Gamma_{r}=\left|\Gamma_{L}\right| \cos \left(\phi \frac{\pi}{180}\right) \\
& \Gamma_{i}=\left|\Gamma_{L}\right| \sin \left(\phi \frac{\pi}{180}\right)
\end{aligned}
$$

With $\phi$ the measured phase and $\left|\Gamma_{L}\right|$ the modulus of the measured amplitude variation of the reflection coefficient expressed as:

$$
\left|\Gamma_{L}\right|=10^{\left(S^{11} / 20\right)}
$$

Unknown impedance reflects a part of the microwave signal. Thus, the amount of reflected signal from the DUT, $\Gamma_{L}$, is directly dependent on the degree of mismatch between the microwave source 
characteristic impedance, $Z_{0}$, (a real industry normalized value of $50 \Omega)$ and the DUT impedance. Its expression can be noted as follows:

$\Gamma_{L}=\frac{V_{\text {refl }}}{V_{\text {inc }}}=\frac{Z_{L}-Z_{0}}{Z_{L}+Z_{0}}=\Gamma_{r}+j \Gamma_{i}$

Where $Z_{L}$ is the unknown impedance of the DUT.

By fixing $Z_{0}$ to $50 \Omega$, we can then define normalized load impedance by

$Z=\frac{Z_{L}}{Z_{0}}=\frac{R+j X}{Z_{0}}=r+j x$

With this simplification, we can rewrite the reflection coefficient formula as:

$\Gamma_{L}=\Gamma_{r}+j \Gamma_{i}=\frac{Z_{L}-Z_{0}}{Z_{L}+Z_{0}}=\frac{\left(Z_{L}-Z_{0}\right) / Z_{0}}{\left(Z_{L}+Z_{0}\right) / Z_{0}}=\frac{Z-1}{Z+1}=\frac{r+j x-1}{r+j x+1}$

and express the normalized load impedance as:

$Z=r+j x=\frac{1+\Gamma_{L}}{1-\Gamma_{L}}=\frac{1+\Gamma_{r}+j \Gamma_{i}}{1-\Gamma_{r}+j \Gamma_{i}}$

By setting the real and the imaginary parts of $Z$, two independent relationships are obtained:

$$
\begin{aligned}
& r=\frac{1-\Gamma_{r}^{2}-\Gamma_{i}^{2}}{\left(1-\Gamma_{r}\right)^{2}+\Gamma_{i}^{2}} \\
& x=\frac{2 \Gamma_{i}}{\left(1-\Gamma_{r}\right)^{2}+\Gamma_{i}^{2}}
\end{aligned}
$$




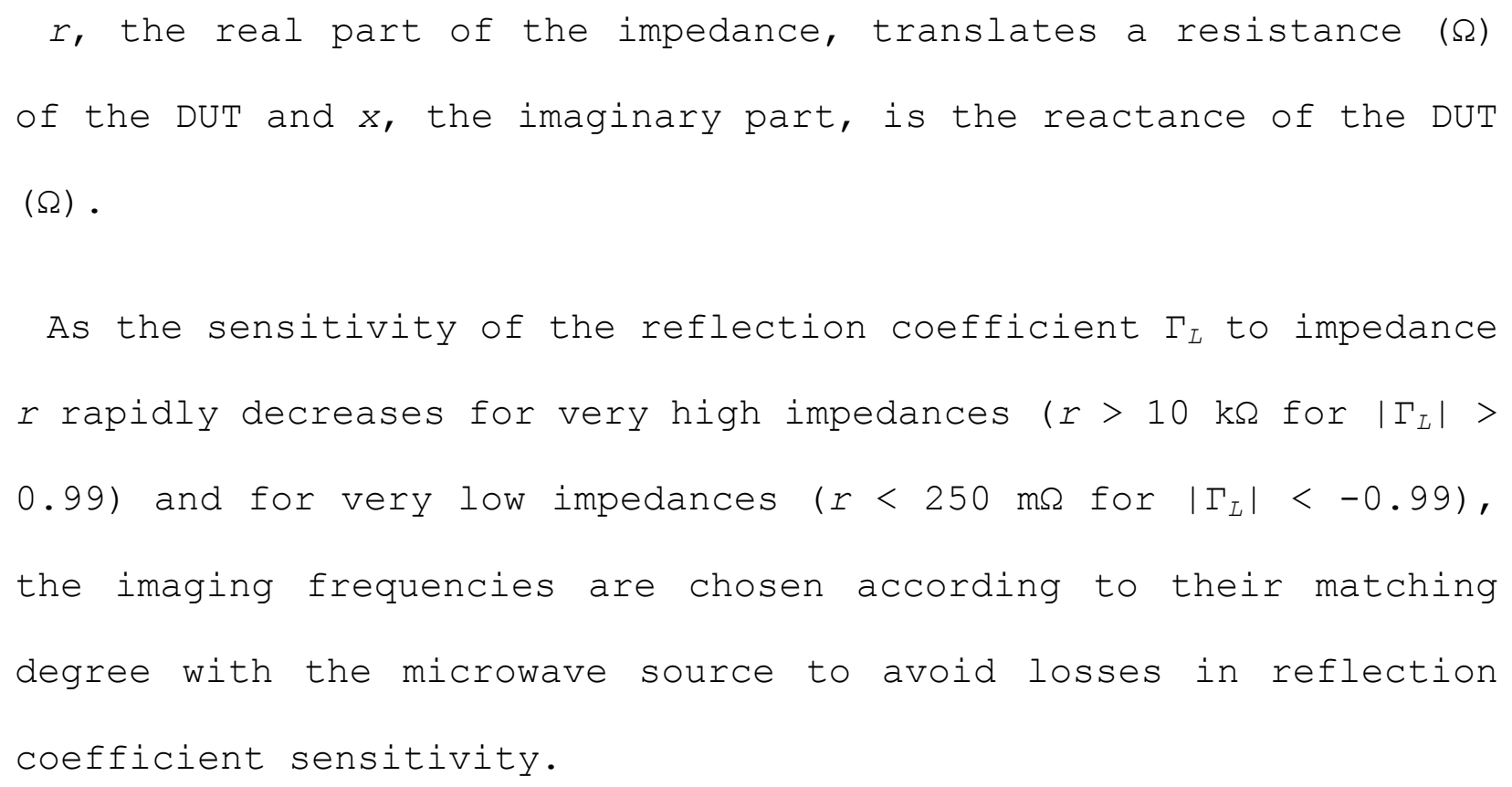

In this article, images representing the variation of the real part of the impedance of the DUT are presented as qualitative measurements (one representative image per condition at $8.6 \mathrm{GHz}$ ).

\section{Data availability}

The data supporting the findings of this study are available from the corresponding author upon reasonable request.

\section{Results and discussion}

\section{Morphology of human oral epithelial cells}

Fig. 1 presents the retention of the salivary mucins MUC5B on human buccal TR146 native cells (Fig. 1b) and on TR146/MUC1 
transfected cells (Fig. 1c) and the topography of native and transfected cells without or with a mucosal pellicle imaged by AFM (Fig. $1 \mathrm{a}$ and $1 \mathrm{~d}$ to 1h). As previously reported[4], the expression of MUC1 in transfected cells enhanced the retention of salivary mucins MUC5B. MUC5B immunostaining showed larger between-cells variability in transfected cells. Cells had a rather flat shape (Fig. 1a) with an apex in height in the range of $1-2 \mu m$. There was no substantial difference in the morphological features of native and transfected cells (Fig. 1d and 1e). Membrane folds (microplicae), a few hundreds of nanometer-high, were visible on both types of cells. They varied in size and density as previously observed by scanning electron microscopy ${ }^{[4]}$. Microplicae are typical of squamous epithelial surfaces ${ }^{[16]}$ where they increase the exchange surface between cells and the external medium, saliva here, with consequences on drug absorption for example. They may also enhance mucus retention thereby preventing infections ${ }^{[16]}$.

The overall appearance of the cell surface was not drastically modified by the presence of a mucosal pellicle on native cells (Fig. 1f). It was not possible to determinate precisely its thickness because of the uneven cells' topography. However, microplicae remained distinguishable under the pellicle as previously found[5b], translating that only a very thin layer was deposited on the cell surface. This is also consistent with former 
measurements of the pellicle's thickness (0 to $100 \mathrm{~nm}$ ) on human buccal cells ${ }^{[17]}$. On transfected cells, the same conclusions applied to most acquired images (Fig. 1g) although a fine filamentous network was also occasionally observed (Fig. 1h). AFM imaging provided a detailed topographic picture of this fragile structure in liquid medium. This network resembles the filamentous structure observed by cryoscanning electron microscopy in submandibular/sublingual saliva, which was interpreted as a mucin network[18]. It is also comparable to a MUC5B network formed on mica observed by AFM[5a]. This distinctive appearance of some TR146/MUC1 cells can be related to the heterogeneous retention of MUC5B (Fig. 1c): it is likely that such a salivary network would form specifically on cells retaining most strongly MUC5B mucins.

\section{Impact of a mucosal pellicle on the hydrophobicity of epithelial cells}

Chemical force microscopy (CFM) with hydrophobic tip has been previously successfully used to performed direct measurement of hydrophobic forces at the cell surfaces [19]. To investigate the impact of a mucosal pellicle on cells' hydrophobicity, we applied CFM with hydrophobic functionalized gold AFM tips to monitor interactions in liquid medium at the cell surface (Fig. 2). Tips were functionalized with alkanethiols terminated with $\mathrm{CH}_{3}$ as 
previously reported ${ }^{[14]}$ and checked on hydrophobic teflon (Supplementary Fig. S1): a greater adhesion force was observed with the functionalized tip. Then the cell surface was scanned leading to adhesion force mapping. Fig. 2a shows a representative map of adhesion force for the four tested conditions. It reveals that there were both attractive (negative values) and repulsive (positive values) forces between the functionalized tip and the cell surface, with large differences among conditions. Pictures of native TR146 cells without (N) or with a mucosal pellicle (NS) were very similar, with attractive and repulsive forces at low intensities. Conversely, much higher intensities (both for positive and negative forces) were recorded on images of TR146/MUC1 transfected cells without ( $T$ ) or with a mucosal pellicle (TS). In addition, the presence of the mucosal pellicle seemed to decrease overall the number of areas with the highest repulsive and attractive forces.

To compare maps, we plotted for each image the cumulative force as a function of the adhesion forces' intensity, both for attractive (negative values) and repulsive (positive values) forces. Fig. 2b provides the resulting curves for the particular images presented in Fig. 2a. This confirmed that attractive and repulsive forces recorded at the surface of native cells without or with a mucosal pellicle were weak since their absolute values 
never exceeded $10 \mathrm{nN}$. The curves were very close for the two conditions N/NS: the presence of saliva hardly modified attractive and repulsive forces at the cell surface. In contrast, the curves obtained for the transfected cells showed higher attractive (down to $-80 \mathrm{nN}$ ) and repulsive (up to $130 \mathrm{nN}$ ) forces. On these cells, the presence of a mucosal pellicle induced a rather large difference in adhesion forces, particularly with a decrease of the maximum intensity of attractive and repulsive forces.

From these curves were extracted the values D25, D50 and D75, which represent respectively the attractive or repulsive forces at 25, 50 and 75 percent of the total attractive or repulsive forces. These were determined for all the acquired images on different cells ( $\mathrm{n}=18,16,18$ and 24 for the conditions $N, T, N S$ and TS respectively). Fig. 2c represents the repulsive and attractive D25, D50 and D75 values (mean \pm STD) while Fig. 2d presents the average repulsive and attractive forces at the cell surface (mean \pm STD). ANOVA testing evidenced statistical differences between conditions for the D25 (repulsive forces: $F=7.92002, p=0.00014$; attractive forces: $\mathrm{F}=10.3863, \mathrm{p}=1.09$ e-05), D50 (repulsive forces: $F=7.69584, p=0.00017$; attractive forces: $F=11.0893, p=5.52 e-06$ ), D75 (repulsive forces: $F=8.99411, \quad p=4.4724 e-05$; attractive forces: $F=11.564, P=3.49$ e-06) and average (repulsive forces: $\mathrm{F}=8.29782, \mathrm{p}=9.22 \mathrm{e}-05$; attractive forces: $\mathrm{F}=10.0733, \mathrm{p}=1.50 \mathrm{e}-05$ ) 
values. Tukey pairwise comparison tests were applied. For native cells, the presence of salivary proteins at the surface (N VS NS) did not modify significantly the repulsive and attractive forces. In contrast, the presence of MUC1 alone ( $\mathrm{N}$ V $\mathrm{T}$ ) significantly increased the adhesive and repulsive forces for all extracted values: D25, D50, D75 and average. The anchoring of salivary proteins on TR146/MUC1 transfected cells (T Vs TS) slightly reduced adhesion forces but not significantly, except for the highest attractive and repulsive forces (D75).

Attractive and repulsive forces suggest the occurrence of noncovalent interactions between the AFM tip and the surface of the cells. Attractive forces could be due to hydrophobic effect, indicating the presence of hydrophobic surfaces, or London dispersion, which are not expected to play an important role due to the weakness of the $\mathrm{CH} \cdot \cdots \mathrm{HC}$ interaction and their too small number, while repulsive forces suggest the presence of hydrophilic surfaces, presenting either formal or partial charges. Therefore, expression of MUC1 increased the intensity of both hydrophobic and charged areas. The protein encoded by the gene used to transfect TR146 cells (MUC1-Y-LSP) presents a shorter extracellular domain than the full-length MUC1. This 167 amino-acids extracellular domain contains 11 basic amino-acids (Arg, Lys) and 15 acidic amino-acids (Asp, Glu), with a theoretical isoelectric point of 
5.08. At the $\mathrm{pH}$ of the cell culture medium (6.8-7.2) or PBS (7.07.8), it tends to be negatively charged, consistently with the increase in repulsive forces. In addition, although the structure of this extracellular domain is not described, its composition in amino-acids suggests that it would comprise both hydrophobic and charged areas, which would explain the present observations. The great variability (indicated by large standard deviations associated to average values) both for attractive and repulsive forces is probably related first to the heterogeneous between- and within-cells expression of MUC1, and second to heterogeneity in the surface properties of MUC1-Y-LSP. This isoform of MUC1 could bear 5 N-glycosylations but in contrast to other isoforms of MUC1 it does not include the variable number tandem repeat (VNTR) module, which is abundantly glycosylated. Thus, this isoform does not fully represent the properties of other isoforms of MUC1, such as MUC1/1. The numerous glycosylations of the VNTR module are expected to be negatively charged increasing the hydrophilicity at the cell surface and should decrease the access to hydrophobic domain of the peptidic chain through steric hindrance.

The presence of salivary proteins decreased the highest attractive and repulsive forces (Fig. $2 \mathrm{c}$ and $2 \mathrm{~d}$ ), suggesting that the most hydrophobic and charged areas participate in the binding of salivary proteins. MUC5B in particular have high affinity for 
hydrophobic substrates ${ }^{[20]}$. Therefore, the highly hydrophobic areas observed upon MUC1 expression probably participate to the higher retention of MUC5B on transfected cells compared to native cells (Fig. 2a and 2b). More generally, our results support the previous suggestion that hydrophobic effects and electrostatic interactions intervene in salivary protein binding during pellicle formation ${ }^{[21]}$.

\section{A mucosal pellicle modifies the dielectric properties of epithelial cells}

After documenting cells' hydrophobicity, we investigated the cells' dielectric properties by scanning microwave microscopy (SMM). This technique has been previously applied to cells [22] where the amplitude of the microwave signal yields information about the sample's conductivity determined for example by the ionic strength, while the phase of the microwave signal reflects the dielectric losses arising from the fluid density/water content characteristic of the sample. An advantage of microwave near field investigation over infrared, optical waves or AFM force field is the penetration ability of microwaves, allowing subsurface imaging even in poorly conductive biological materials. Since penetration decreases with increasing frequency, it is possible to estimate whether differences in dielectric properties occur at the sample surface or deeper. 
The samples were analysed with a scanning microwave microscope set up as shown in Fig. 3. In the imaging mode where a fixed frequency is chosen, SMM allows to simultaneously obtain the topography of the surface by means of its AFM tip and the reflection coefficient of the microwave signal acquired by the vector network analyzer at each point of measurement. The microwave amplitude and phase images are dependent on the frequency as well as the topography of the cells. In our case, the topography was overall comparable from one sample to another as shown by AFM images (Fig. 1 and Fig. 4a). Any significant difference in the amplitude and phase SMM images relates therefore mainly to differences in dielectric properties among samples.

Each sample was examined at resonance frequencies of $2,4.3$ and 8.6 GHz. A typical topography image of each type of sample is displayed with the corresponding SMM amplitude and phase images obtained at a resonance frequency of $8.6 \mathrm{GHz}$ (Fig. 4). SMM images obtained at 2 and $4.3 \mathrm{GHz}$ are presented in Supplementary Fig. S2. Overall, the contrast of amplitude and phase images between samples increased with resonance frequency (Fig. S2). The difference in dielectric properties between cells was therefore much more visible at high frequency (near the sample's surface) than at low frequency (deeper down). This is expected since cells differ by 
the presence or not of a transmembrane mucin, and the presence or not of a mucosal pellicle on their surface.

The impact of MUC1 expression on electric properties was evaluated by comparing native and transfected cells at $4.3 \mathrm{GHz}$ and 8.6 GHz (Fig. 4e). At 4.3Ghz, the amplitude microwave signal was significantly higher for native cells ( $\mathrm{DF}=30, \mathrm{~F}=12.70, \mathrm{p}=0.0012)$. At $8.6 \mathrm{GHz}$, amplitude and phase signals were significantly higher for transfected cells (amplitude: $\mathrm{DF}=25, \mathrm{~F}=6.29, \mathrm{p}=0.0190$; phase: $\mathrm{DF}=24, \mathrm{~F}=10.63, \mathrm{p}=0.0033)$. The large differences in values at $8.6 \mathrm{GHz}$ (e.g. phase of $\sim 0.060$ deg $\mathrm{Vs} \sim 0.50$ deg for $\mathrm{N}$ and $\mathrm{T}$, respectively) confirm that the microwave-sample interactions differed mainly near the sample's surface, most likely as a result of the presence of the transmembrane protein. MUC1-Y-LSP contains a short cytoplasmic tail, a membrane-spanning domain and an extracellular domain overall negatively charged. Charge variations induced by the presence of MUC1 possibly influenced the complex conductivity, thereby the SMM amplitude and phase signals.

The impact of a mucosal pellicle on electric properties was evaluated by comparing both native and transfected cells without or with a mucosal pellicle at 4.3 and $8.6 \mathrm{GHz}$ (Fig. 4f). For both cell types, the presence of the pellicle had no significant impact on the SMM amplitude signal. In contrast, the SMM phase signal was 
significantly increased ( $\mathrm{DF}=17, \mathrm{~F}=6.38, \mathrm{p}=0.0217)$ after pelicle formation for native cells at $8.6 \mathrm{GHz}$.

The difference in phase signals of $N$ and $N S$ cells indicated a change in the dielectric environment of the material due to the mucosal pellicle. This change was larger in absolute value at high frequency $(8.6 \mathrm{GHz})$ i.e. near the surface. At microwave frequencies, the dielectric properties of biological tissues are highly influenced by the presence of water. For example, a SMM study on Chinese hamster ovary cells reported that increasing the relative humidity raised their conductance[23] since water adsorbed onto the cells' surface is responsible for the dissipation of microwave energy. With an increase in humidity content, the dielectric loss values (translated by the phase of the microwave signal) increase. Our results are in line with this: the mucosal pellicle most likely increased residual humidity at the cells' surface.

Results of phase signal for transfected cells were rather unexpected: the presence of MUC1 promotes binding of MUC5B on the cells' surface and enhances mucosal pellicle formation [4], which was expected to result in higher dielectric losses. Nevertheless, a slight increase in microwave phase signal was observed in TS in comparison to NS $(0.30$ deg vs 0.23 deg) which may relate to a higher wettability of the cell surface. Thus, a direct correlation 
between mucins concentrations and wettability of saliva was reported: saliva containing more MUC5B presented lower contact angles ${ }^{[18]}$. Assuming there is an increase in surface wettability in transfected vs native cell, this would explain the higher microwave phase signal. The only representation of microwave raw signals (phase and amplitude), however, is not sufficient to fully understand the impact of saliva on dielectric properties of native and transfected cells.

Biological media are defined by their complex conductivity and permittivity, these properties varying with the frequency of the electric field passing through the medium. In our case, the complex reflection coefficient can be converted into complex impedance in order to obtain electrical and dielectric properties, i.e. capacitance and conductance properties of the sample [24]. Fig. 5 shows impedance images deduced from phase and amplitude values for one representative image per condition N, T, NS and TS at 8.6 GHz (Fig 5a to 5d). After mucosal pellicle formation, the maximum impedance increased. Saliva, containing 99\% of water, can be considered as a polar dielectric system. When a dielectric material is excited by an electric field at microwave frequencies, the rotational movement is no longer synchronized with the variations of the electric field and a resonance phenomenon occurs. There is thus a phase difference between the electric field and the 
rotational movement, thereby producing dielectric losses, translated into the impedance increase which was observed. Even more remarkably, the 3D impedance images show that this effect is different between the two cell types. For native cells specifically (Fig. 5c), the effect is characterized by the dissociation of the impedance of the native cells (low level) from that induced by the mucosal pellicle formation (high level) which can be interpreted as a low affinity of native cells for saliva, in accordance with the hydrophobic functionalized tip results. In contrast for transfected cells, the impedance response is not dissociated. With the presence of an electric field, the effects on the impedance are complex: they combine first a dielectric loss effect due to, as previously mentioned, increasing binding between transmembrane MUC1 and salivary MUC5B and thereby formation of the mucosal pellicle and second a conductivity effect induced by the displacement of the charges in dense areas. The present impedance results indicate a strong binding between the transfected cells and the mucosal pellicle.

\section{Conclusion}

The present study innovatively combines different techniques and methodologies of atomic force microscopy, in order to 
characterize the surface properties of a model of mucosa. Classical AFM technique brought information on the topography of the cells and the structure of the mucosal pellicle. Chemical force microscopy (CFM) investigation, with CH3 functionalized tip allowed to characterize the hydrophobicity at the cell surface and revealed that the expression of MUC1 leads to the presence at the cells' surface of more repulsive and attractive forces suggesting an increase of both hydrophobic and hydrophilic areas. It indicates also that the adhesion of the salivary proteins involves probably the most hydrophobic and charged areas of MUC1. The SMM approach gave complementary information on the electric properties of the cell surface and the main results obtained indicate that salivary proteins and MUC1 are strongly interacting together. In absence of MUC1, salivary proteins appeared as a distinct layer poorly interacting with the cells' surface.

These findings open perspectives about the use of AFM to characterize biological structures and their formation. Regarding the oral mucosa and the formation of the mucosal pellicle, these results call for research aiming at gaining a deeper understanding of the mechanisms involved in the formation of the mucosal pellicle and the regions or domains of MUC1 which are involved in the binding of salivary proteins. Future research is also required to 
1

2

3 4

5

6

7

8

9

10

11

12

13

14

15

16

17

18

19

20

21

22

23

24

25

26

27

28

29

30

31

32

33

34

35

36

37

38

39

40

41

42

43

44

45

46

47

48

49

50

51

52

53

54

55

56

57

58

59

60

identify the salivary proteins which specifically bind MUC1 and the noncovalent interactions involved. 


\section{FIGURES}

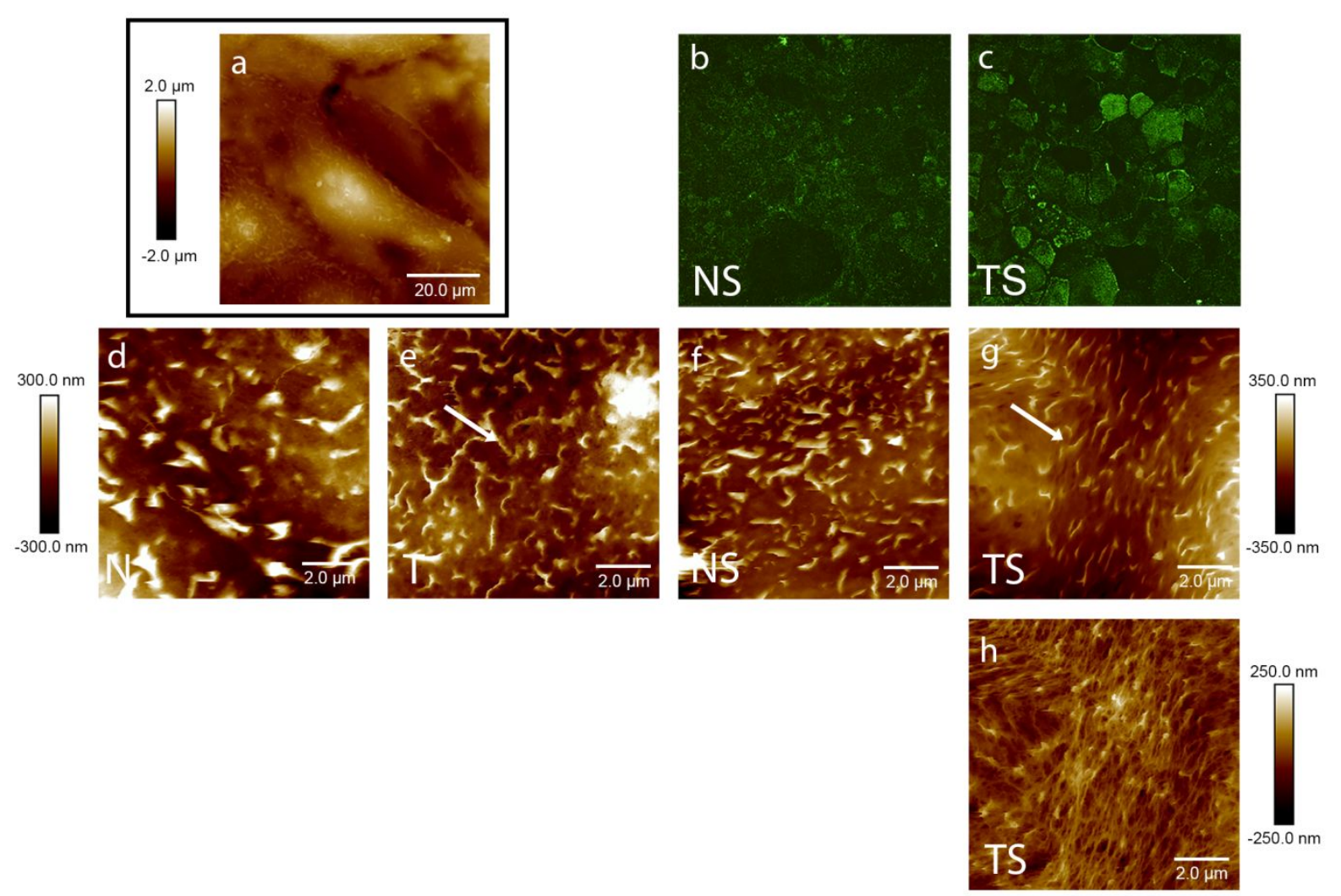

Figure 1. Retention of salivary mucins and topography of human epithelial buccal cells. Immuno-staining of MUC5B bound at the cell surface of native TR146 cells (b) and transfected TR146/MUC1 cells (c). Typical topographical image of epithelial cells (here are presented TR146/MUC1 cells) (a). Topography of TR146 native cells (d), TR146/MUC1 transfected cells (e), native cells with a mucosal pellicle (f) and transfected cells with a mucosal pellicle $(g, h)$. 

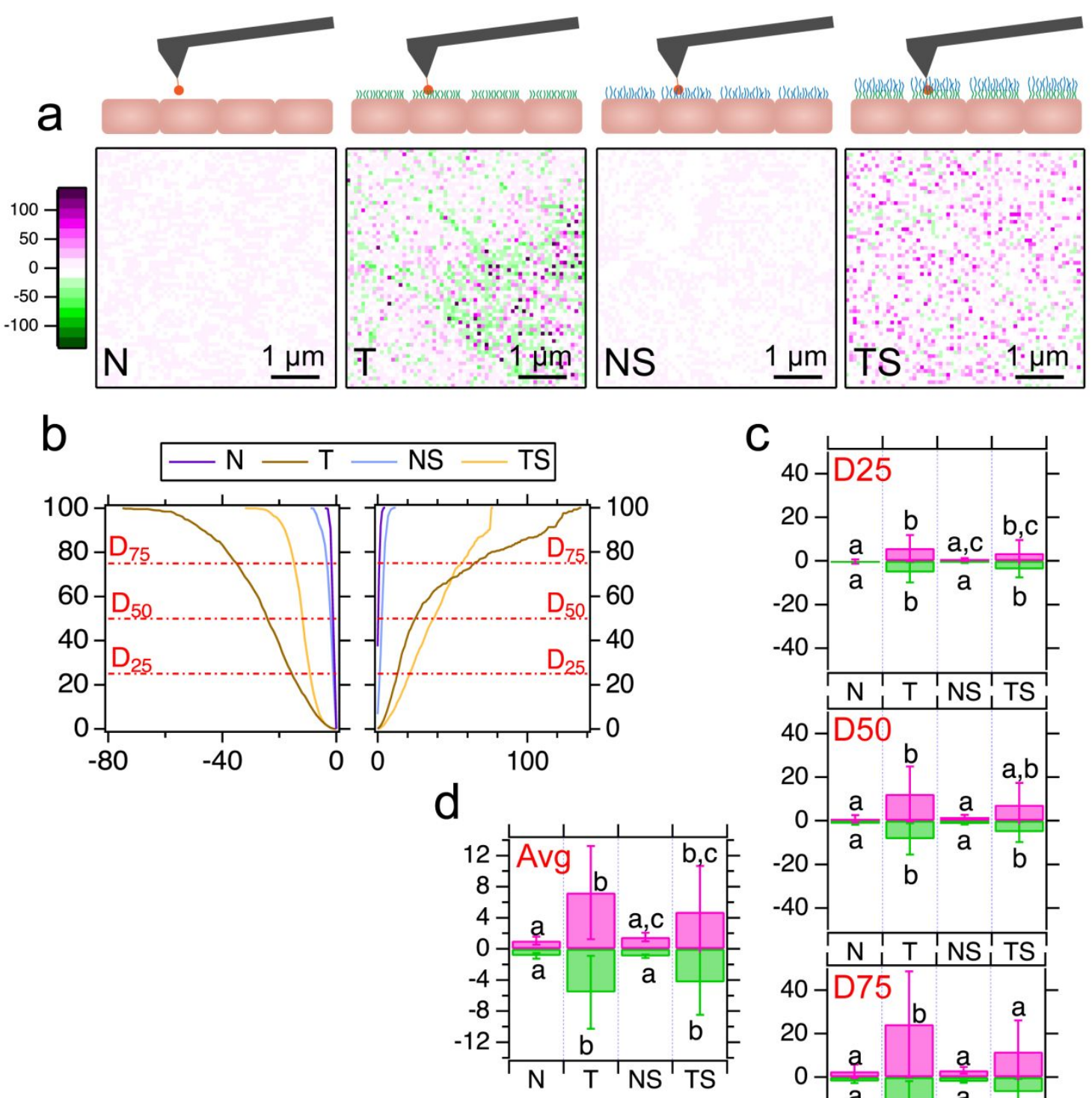

\section{C}

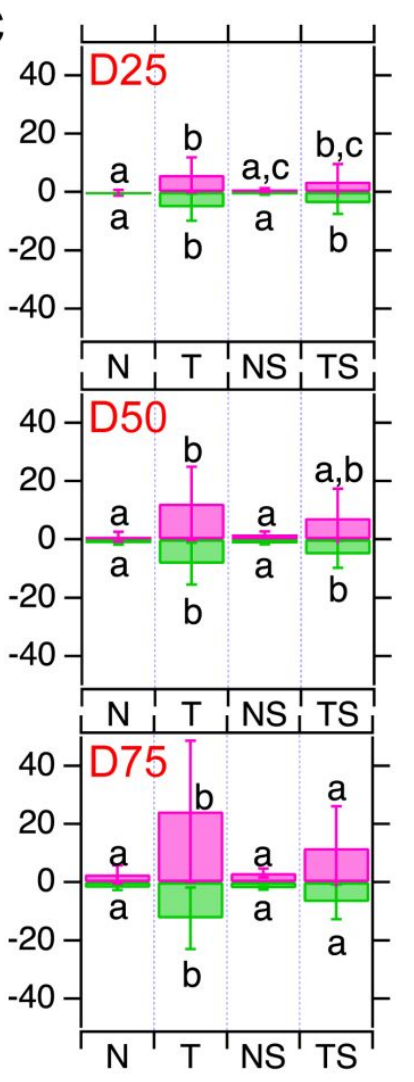

Figure 2. Hydrophobicity of human epithelial buccal cells. a. Schematic illustration of sample-tip interactions and corresponding adhesion force maps are given for TR146 native cells (N), TR146/MUC1 transfected cells (T), native cells with a mucosal pellicle (NS) and transfected cells with a mucosal pellicle (TS), respectively. b. Cumulated attractive (left) and repulsive (right) force curves as a function of force intensity. c. Means of the D75, D50 and D25 positive and negative value. d. Means of the average values of repulsive and attractive forces. All forces are expressed in $\mathrm{nN}$. 


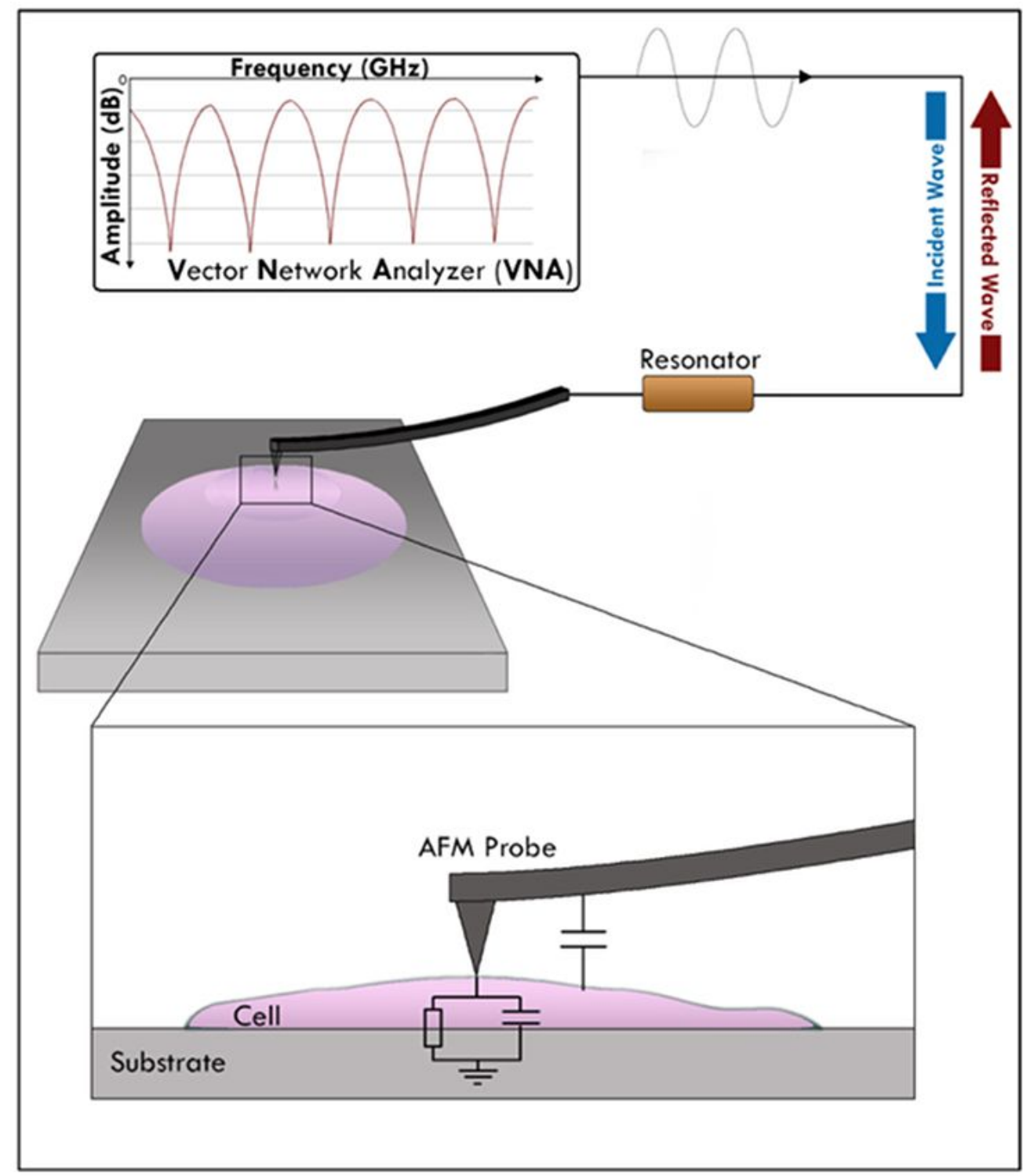

Figure 3. Schematic illustration of cell analysis by scanning microwave microscopy. 
N $\mathbf{T}$

NS

TS

Topography



b

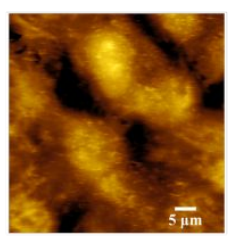

C

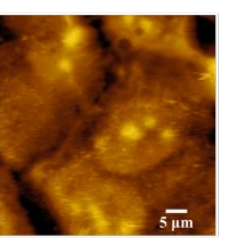

d

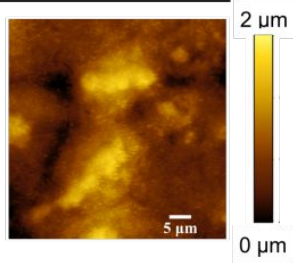

SMM Amplitude

$a^{\prime}$

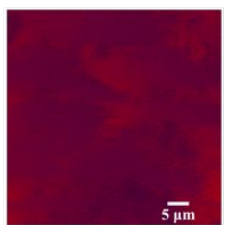

b'
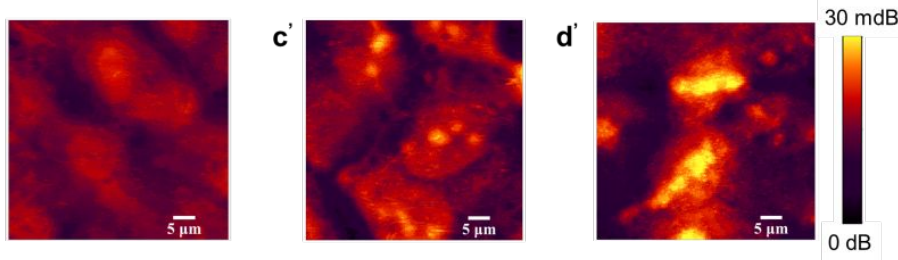

SMM Phase

$a^{*}$
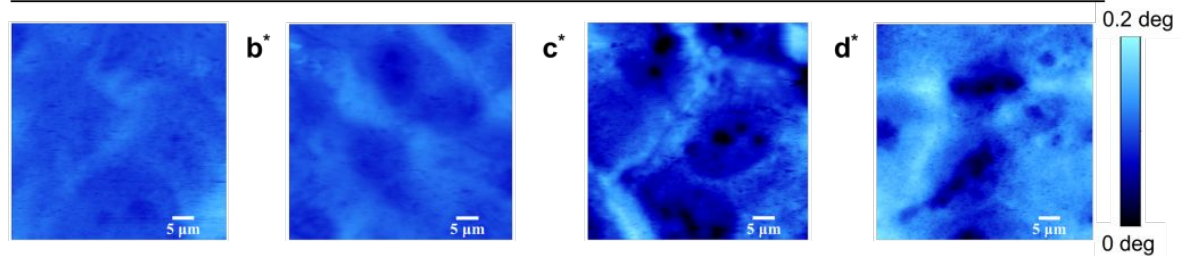

e Impact of MUC1
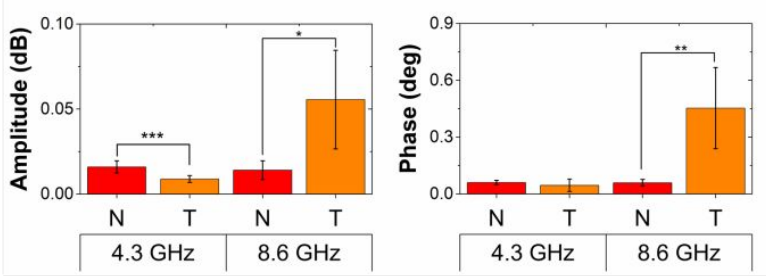

f Impact of a salivary pellicle
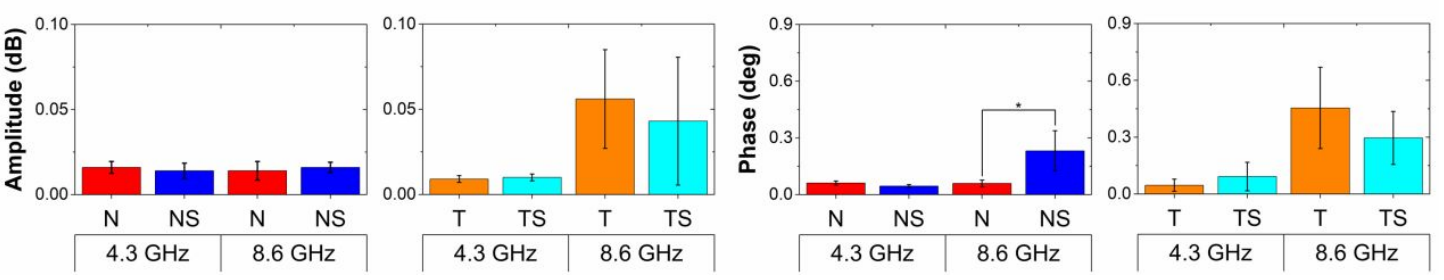

Figure 4. Scanning microwave microscopy analysis of human epithelial buccal cells. Topography (a-d), SMM amplitude $\left(a^{\prime}-d^{\prime}\right)$ and SMM phase (a*-d*) images for TR146 native cells (N), TR146/MUC1 transfected cells $(\mathrm{T})$, native cells with a mucosal pellicle (NS) and transfected cells with a mucosal pellicle (TS). SMM amplitude and phase images were measured at a resonance frequency of 8.6 $\mathrm{GHz}$. All images are at 50 x $50 \mu \mathrm{m}^{2}$ scanning size.

e, f: SMM amplitude and phase values (mean \pm STD) recorded at 4.3 and $8.6 \mathrm{GHz}$ for native (red) and transfected (orange) cells, native cells with a mucosal pellicle (dark blue) and transfected cells with a mucosal pellicle (light blue). ANOVA tests were 
performed to evaluate the statistical impact of the presence of MUC1 protein (e) or a mucosal pellicle (f) on amplitude and phase values $(* \mathrm{p}<0.05, \star \star \mathrm{p}<0.005$ and $\star \star \star \mathrm{p}<0.001)$. 


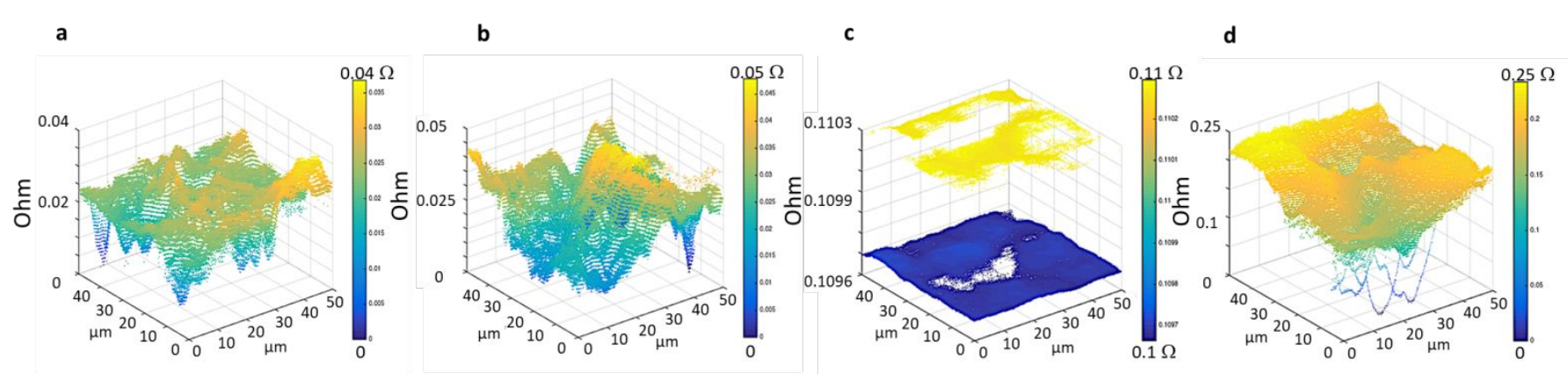

Figure 5. Impedance images of TR146 epithelial buccal cells. Impedance images were constructed for one representative image per condition from amplitude and phase values obtained at 8.6GHz. a: TR146 native cells (N), b: TR146/MUC1 transfected cells (T), $\mathbf{c}:$ native cells with a mucosal pellicle (NS) and d: transfected cells with a mucosal pellicle (TS). 
ASSOCIATED CONTENT

Supporting Information.

\section{Supporting Figure 51 . Verification of AFM tips functionalization. \\ Supporting Figure S2. Scanning microwave microscopy analysis of human epithelial buccal cells.}

\section{AUTHOR INFORMATION \\ Corresponding Author \\ Francis Canon}

\section{Author Contributions}

E.N.A., E.B., E.L and F.C. Conceived and designed the work. E.N.A. performed all the AFM experiments. S.P. and M.B. produced the TR146/MUC1 cells, maintained the cell lines and performed immunohistochemistry. B.D.F. calculated and plotted impedance images. E.N.A., E.B., M.M., E.L and F.C analyzed and interpreted the data. E.N.A. drafted the manuscript with input from all authors. E.B., B.D.F., M.M., E.L. and F.C. revised the manuscript. All authors have approved its submitted version.

\section{Funding Sources}


This study was funded by the French National Research Agency (Grant ANR-14-CE20-0001-01 MUFFIN). The French National Research Agency also provided support for establishing and maintaining collaboration between ICB and INRA (Grants ANR-15-IDEX-03 PIA2/iSite-BFC, ANR-15-CE09-0002-02, ANR-17-EURE-0002 EIPHI Graduate School).

\title{
ACKNOWLEDGMENT
}

This study was funded by the French National Research Agency (Grant ANR-14-CE20-0001-01 MUFFIN). The French National Research Agency also provided support for establishing and maintaining collaboration between ICB and INRA (Grants ANR-15-IDEX-03 PIA2/iSite-BFC, ANR-15-CE09-0002-02, ANR-17-EURE-0002 EIPHI Graduate School).

\begin{abstract}
ABBREVIATIONS
AFM, atomic force microscopy; MUC1, Mucine-1; MUC5B, Mucine-5B; N, native cells; NS, native cells with a mucosal pellicle; PBS, phosphate-buffered saline; SMM, scanning microwave microscopy; T, TR146/MUC1 transfected cells; TS, transfected cells with a mucosal pellicle; VNA, vector network analyzer.
\end{abstract}

REFERENCES 
[1] a) S. D. Bradway, E. J. Bergey, F. A. Scannapieco, N. Ramasubbu, S. Zawacki, M. J. Levine, Formation of SalivaryMucosal Pellicle - the Role of Transglutaminase, Biochemical Journal 1992, 284, 557-564; b) H. L. Gibbins, G. B. Proctor, G. E. Yakubov, S. Wilson, G. H. Carpenter, Concentration of salivary protective proteins within the bound oral mucosal pellicle, Oral Diseases 2013, n/a-n/a.

[2] a) L. A. Tabak, Structure and function of human salivary mucins, Critical Reviews in Oral Biology and Medicine 1990, 1, 229-234; b) C. Hannig, M. Hannig, M. Morzel, in Flavour: From Food to Perception (Eds.: E. Guichard, C. Salles, M. Morzel, A.-M. L. Bon), John Wiley \& Sons; Ltd 2017, pp. 79108 .

[3] H. L. Gibbins, G. E. Yakubov, G. B. Proctor, S. Wilson, G. H. Carpenter, What interactions drive the salivary mucosal pellicle formation?, Colloids and Surfaces B-Biointerfaces 2014, 120, 184-192.

[4] S. Ployon, C. Belloir, A. Bonnotte, J. Lherminier, F. Canon, M. Morzel, The membrane-associated MUC1 improves adhesion of salivary MUC5B on buccal cells. Application to development of an in vitro cellular model of oral epithelium, Arch. Oral Biol. 2016, 61, 149-155.

[5] a) H. S. Davies, P. D. A. Pudney, P. Georgiades, T. A. Waigh, N. W. Hodson, C. E. Ridley, E. W. Blanch, D. J. Thornton, Reorganisation of the Salivary Mucin Network by Dietary Components: Insights from Green Tea Polyphenols, PLOS ONE 2014, 9; b) S. Ployon, M. Morzel, C. Belloir, A. Bonnotte, E. Bourillot, L. Briand, E. Lesniewska, J. Lherminier, E. Aybeke, F. Canon, Mechanisms of astringency: Structural alteration of the oral mucosal pellicle by dietary tannins and protective effect of bPRPs, Food Chemistry 2018, 253, 79-87.

[6] S. Ployon, M. Morzel, F. Canon, The role of saliva in aroma release and perception, Food Chemistry 2017, 226, 212-220.

[7] L. F. Garcia-Alles, E. Lesniewska, K. Root, N. Aubry, N. Pocholle, C. I. Mendoza, E. Bourillot, K. Barylyuk, D. Pompon, R. Zenobi, D. Reguera, G. Truan, Spontaneous noncanonical assembly of CcmK hexameric components from betacarboxysome shells of cyanobacteria, Plos One 2017, 12, 30.

[8] a) D. Alsteens, R. Newton, R. Schubert, D. Martinez-Martin, M. Delguste, B. Roska, D. J. Muller, Nanomechanical mapping of first binding steps of a virus to animal cells, Nat. Nanotechnol. 2017, 12, 177-183; b) E. N. Aybeke, G. Belliot, S. Lemaire-Ewing, M. Estienney, Y. Lacroute, P. Pothier, E. Bourillot, E. Lesniewska, HS-AFM and SERS Analysis of Murine Norovirus Infection: Involvement of the Lipid Rafts, Small 2017, 13, 10. 
[9] A. X. Cartagena-Rivera, W. H. Wang, R. L. Geahlen, A. Raman, Fast, multi-frequency, and quantitative nanomechanical mapping of live cells using the atomic force microscope, Sci Rep 2015, 5, 11.

[10] a) Y. Harada, M. Kuroda, A. Ishida, Specific and quantized antigen-antibody interaction measured by atomic force microscopy, Langmuir 2000, 16, 708-715; b) A. Berthier, C. Elie-Caille, E. Lesniewska, R. Delage-Mourroux, W. Boireau, Label-free sensing and atomic force spectroscopy for the characterization of protein-DNA and protein-protein interactions: application to estrogen receptors, J. Mol. Recognit. 2011, 24, 429-435.

[11] C. Plassard, E. Bourillot, J. Rossignol, Y. Lacroute, E. Lepleux, L. Pacheco, E. Lesniewska, Detection of defects buried in metallic samples by scanning microwave microscopy, Phys. Rev. B 2011, 83, 4.

[12] J. C. Love, L. A. Estroff, J. K. Kriebel, R. G. Nuzzo, G. M. Whitesides, Self-assembled monolayers of thiolates on metals as a form of nanotechnology, Chem. Rev. 2005, 105, $1103-1169$.

[13] R. G. Nuzzo, D. L. Allara, Adsorption of bifunctional organic disulfides on gold surfaces, Journal of the American Chemical Society 1983, 105, 4481-4483.

[14] L. S. Dorobantu, S. Bhattacharjee, J. M. Foght, M. R. Gray, Atomic force microscopy measurement of heterogeneity in bacterial surface hydrophobicity, Langmuir 2008, 24, 49444951.

[15] I. Horcas, R. Fernandez, J. M. Gomez-Rodriguez, J. Colchero, J. Gomez-Herrero, A. M. Baro, WSXM: A software for scanning probe microscopy and a tool for nanotechnology, Rev. Sci. Instrum. 2007, 78, 8.

[16] P. Asikainen, E. Sirvio, J. J. W. Mikkonen, S. P. Singh, E. A. J. M. Schulten, C. M. ten Bruggenkate, A. P. Koistinen, A. M. Kullaa, Microplicae - Specialized Surface Structure of Epithelial Cells of Wet-Surfaced Oral Mucosa, Ultrastructural Pathology 2015, 39, 299-305.

[17] M. Morzel, S. Tai, H. Brignot, J. Lherminier, Immunocytological detection of salivary mucins (MUC5B) on the mucosal pellicle lining human epithelial buccal cells, Microsc. Res. Tech. 2014, 77, 453-457.

[18] A. Vijay, T. Inui, M. Dodds, G. Proctor, G. Carpenter, Factors That Influence the Extensional Rheological Property of Saliva, PLOS ONE 2015, 10.

[19] D. Alsteens, E. Dague, P. G. Rouxhet, A. R. Baulard, Y. F. Dufrêne, Direct Measurement of Hydrophobic Forces on Cell Surfaces Using AFM, Langmuir 2007, 23, 11977-11979. 
[20] L. Lindh, P. O. Glantz, I. Carlstedt, C. Wickstrom, T. Arnebrant, Adsorption of MUC5B and the role of mucins in early salivary film formation, Colloids and Surfaces BBiointerfaces 2002, 25, 139-146.

[21] S. D. Bradway, E. J. Bergey, P. C. Jones, M. J. Levine, Oral Mucosal Pellicle - Adsorption and Transpeptidation of Salivary Components to Buccal Epithelial-Cells, Biochemical Journal 1989, 261, 887-896.

[22] Y. J. Oh, H. P. Huber, M. Hochleitner, M. Duman, B. Bozna, M. Kastner, F. Kienberger, P. Hinterdorfer, High-frequency electromagnetic dynamics properties of THP1 cells using scanning microwave microscopy, Ultramicroscopy 2011, 111, 1625-1629.

[23] S. S. Tuca, G. Badino, G. Gramse, E. Brinciotti, M. Kasper, Y. J. Oh, R. Zhu, C. Rankl, P. Hinterdorfer, F. Kienberger, Calibrated complex impedance of CHO cells and E. coli bacteria at $\mathrm{GHz}$ frequencies using scanning microwave microscopy, Nanotechnology 2016, 27, 9.

[24] G. Gramse, M. Kasper, L. Fumagalli, G. Gomila, P. Hinterdorfer, F. Kienberger, Calibrated complex impedance and permittivity measurements with scanning microwave microscopy, Nanotechnology 2014, 25, 8 . 


\section{SYNOPSIS}

\section{Mucosal pellicle}
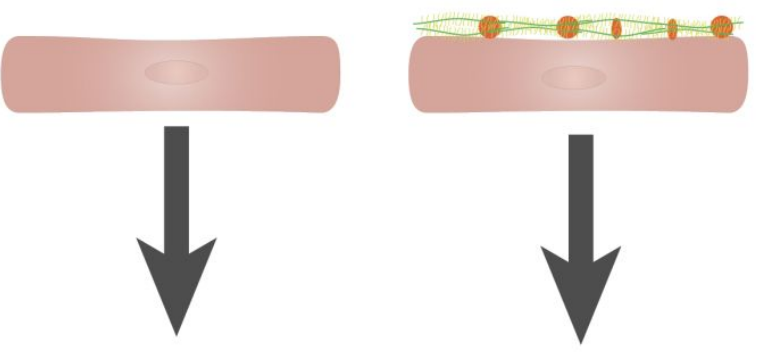
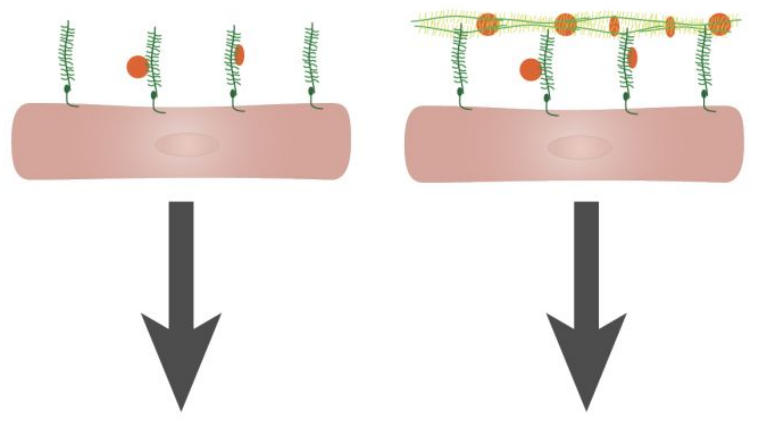

Topography

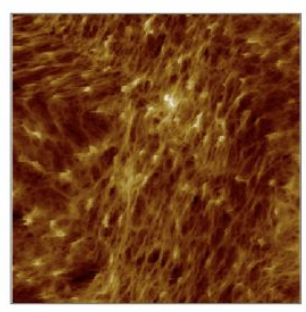

Hydrophobicity Electric properties
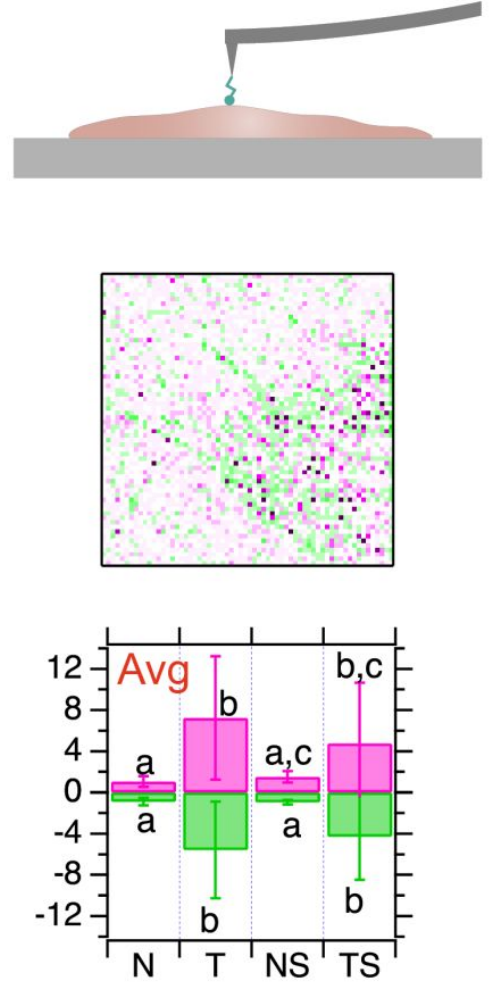
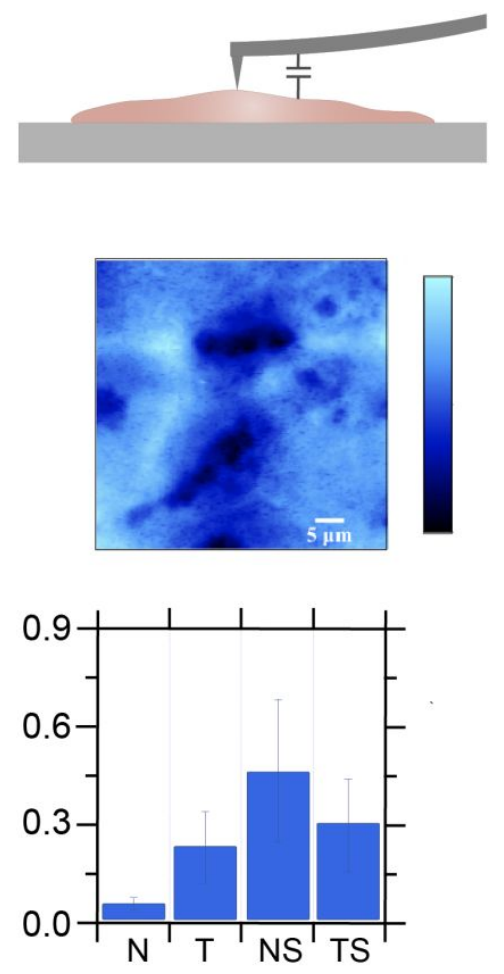
Figure 1. Retention of salivary mucins and topography of human epithelial buccal cells. Immuno-staining of MUC5B bound at the cell surface of native TR146 cells (b) and transfected TR146/MUC1 cells (c). Typical topographical image of epithelial cells (here are presented TR146/MUC1 cells) (a). Topography of TR146 native cells (d), TR146/MUC1 transfected cells (e), native cells with a mucosal pellicle (f) and transfected cells with a mucosal pellicle $(g, h)$. 

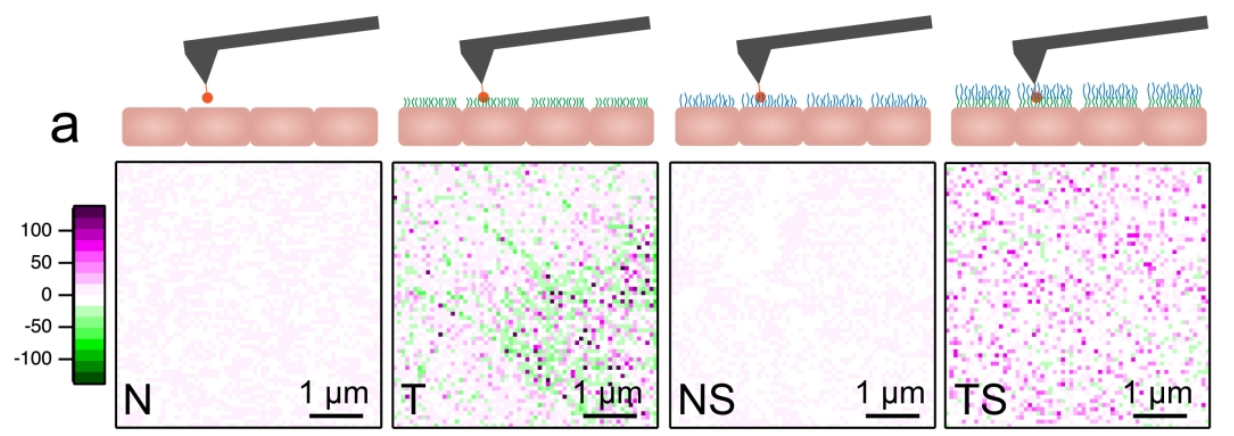

b
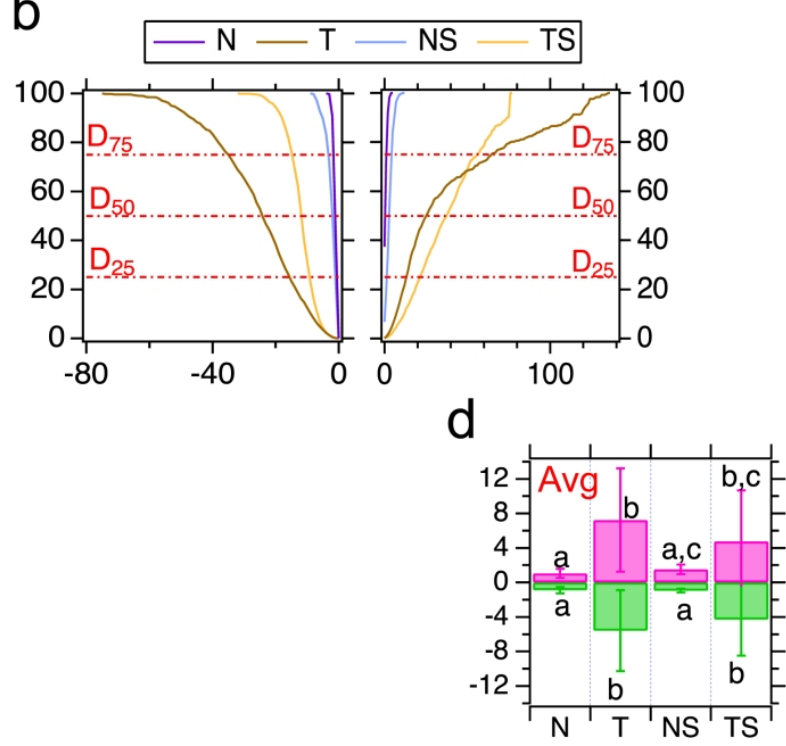

C

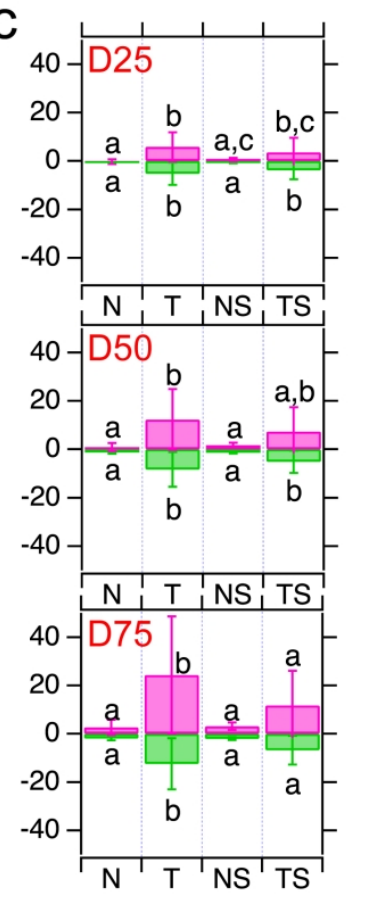

Figure 2. Hydrophobicity of human epithelial buccal cells. a. Schematic illustration of sample-tip interactions and corresponding adhesion force maps are given for TR146 native cells (N), TR146/MUC1 transfected cells (T), native cells with a salivary pellicle (NS) and transfected cells with a salivary pellicle (TS), respectively. b. Cumulated attractive (left) and repulsive (right) force curves as a function of force intensity. c. Means of the D75, D50 and D25 positive and negative value. d. Means of the average values of repulsive and attractive forces. All forces are expressed in $\mathrm{nN}$. 


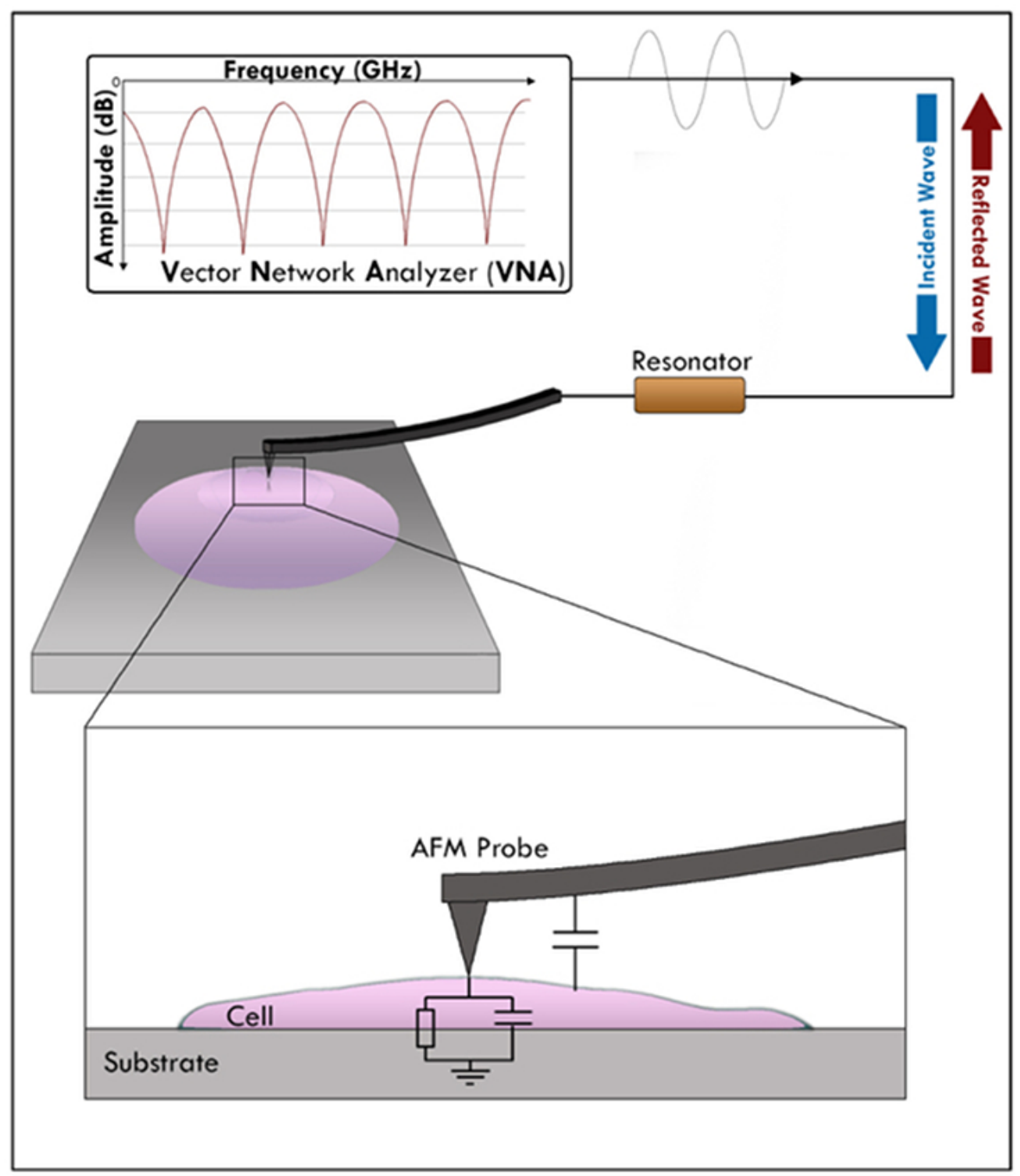

Figure 3. Schematic illustration of cell analysis by scanning microwave microscopy. $61 \times 71 \mathrm{~mm}(300 \times 300 \mathrm{DPI})$ 
Figure 4. Scanning microwave microscopy analysis of human epithelial buccal cells. Topography (a-d), SMM amplitude $\left(a^{\prime}-d^{\prime}\right)$ and SMM phase $\left(a^{*}-d^{*}\right)$ images for TR146 native cells (N), TR146/MUC1 transfected cells

$(T)$, native cells with a salivary pellicle (NS) and transfected cells with a salivary pellicle (TS). SMM amplitude and phase images were measured at a resonance frequency of $8.6 \mathrm{GHz}$. All images are at $50 \times 50$ $\mu \mathrm{m} 2$ scanning size.

e, f: SMM amplitude and phase values (mean +/- STD) recorded at 4.3 and $8.6 \mathrm{GHz}$ for native (red) and transfected (orange) cells, native cells with a salivary pellicle (dark blue) and transfected cells with a salivary pellicle (light blue). ANOVA tests were performed to evaluate the statistical impact of the presence of MUC1 protein (e) or a salivary pellicle (f) on amplitude and phase values $(* p<0.05, * * p<0.005$ and $* * * p<0.001)$. 


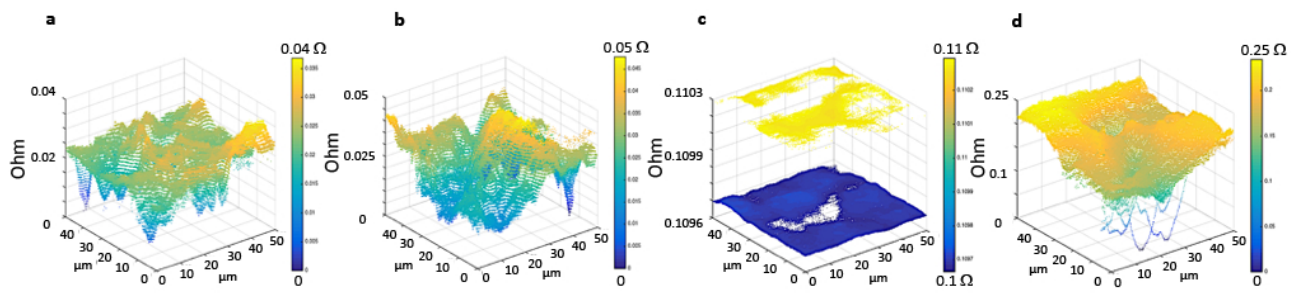

Figure 5. Impedance images of human epithelial buccal cells. Impedance images were constructed for one representative image per condition from amplitude and phase values obtained at $8.6 \mathrm{GHz}$. a: TR146 native cells (N), b: TR146/MUC1 transfected cells (T), c: native cells with a salivary pellicle (NS) and d: transfected cells with a salivary pellicle (TS). 